- In China, Japan and South Korea, Go is hugely popular and is even played by celebrity professionals. But the game has long interested AI researchers because of its complexity. The rules are relatively simple: the goal is to gain the most territory by placing and capturing black and white stones on a $19 \times 19$ grid. But the average 150 -move game contains more possible board configurations $-10^{170}-$ than there are atoms in the Universe, so it can't be solved by algorithms that search exhaustively for the best move.

\section{ABSTRACT STRATEGY}

Chess is less complex than Go, but it still has too many possible configurations to solve by brute force alone. Instead, programs cut down their searches by looking a few turns ahead and judging which player would have the upper hand. In Go, recognizing winning and losing positions is much harder: stones have equal values and can have subtle impacts far across the board.

To interpret Go boards and to learn the best possible moves, the AlphaGo program applied deep learning in neural networks - braininspired programs in which connections between layers of simulated neurons are strengthened through examples and experience. It first studied 30 million positions from expert games, gleaning abstract information on the state of play from board data, much as other programmes categorize images from pixels (see Nature 505, 146-148; 2014). Then it played against itself across 50 computers, improving with each iteration, a technique known as reinforcement learning.

The software was already competitive with the leading commercial Go programs, which select the best move by scanning a sample of simulated future games. DeepMind then combined this search approach with the ability to pick moves and interpret Go boards - giving "Deep learning AlphaGo a better idea of which strategies are likely to be successful. The technique is "phenomenal", says Jonathan Schaeffer, a computer scientist at the University of Alberta in Edmonton, Canada, whose software Chinook solved ${ }^{3}$ draughts in 2007. Rather than follow the trend of the past 30 years of trying to crack games using computing power, DeepMind has reverted to mimicking human-like knowledge, albeit by training, rather than by being programmed, he says. The feat also shows the power of deep learning, which is going from success to success, says Coulom. "Deep learning is killing every problem in AI."

AlphaGo plays in a human way, says Fan. "If no one told me, maybe I would think the player was a little strange, but a very strong player, a real person." The program seems to have developed a conservative (rather than aggressive) style, adds Toby Manning, a lifelong Go player who refereed the match.

Google's rival firm Facebook has also been working on software that uses machine learning to play Go. Its program, called darkforest, is still behind commercial state-of-the-art Go AI systems, according to a November preprint ${ }^{4}$.

Hassabis says that many challenges remain in DeepMind's goal of developing a generalized AI system. In particular, its programs cannot yet usefully transfer their learning about one system — such as Go - to new tasks; a feat that humans perform seamlessly. "We've no idea how to do that. Not yet," Hassabis says.

Go players will be keen to use the software to improve their game, says Manning, although Hassabis says that DeepMind has yet to decide whether it will make a commercial version.

AlphaGo hasn't killed the joy of the game, Manning adds. Strap lines boasting that Go is a game that computers can't win will have to be changed, he says. "But just because some software has got to a strength that I can only dream of, it's not going to stop me playing." SEE EDITORIAL P.437

1. Silver, D. et al. Nature 529, 484-489 (2016).

2. Mnih, V. et al. Nature 518, 529-533 (2015)

3. Schaeffer, J. et al. Science 317, 1518-1522 (2007).

4. Tian, Y. \& Zhu, Y. Preprint at arXiv http://arxiv.org/ pdf/1511.06410.pdf (2015).

\section{BY HEIDI LEDFORD}

A ddie plays hard for an 11-year-old greater Swiss mountain dog - she will occasionally ignore her advanced years to hurl her 37-kilogram body at an unwitting house guest in greeting. But she carries a mysterious burden: when she was 18 months old, she started licking her front legs aggressively enough to wear off patches of fur and draw blood.

Addie has canine compulsive disorder - a condition that is thought to be similar to human obsessive-compulsive disorder (OCD). Canine compulsive disorder can cause dogs to chase their tails for hours on end, or to suck on a toy or body part so compulsively that it interferes with their eating or sleeping.

Addie may soon help researchers to determine why some dogs are more prone to the disorder than others. Her owner, Marjie Alonso of Somerville, Massachusetts, has enrolled her in a project called Darwin's Dogs, which aims to compare information about the behaviour of thousands of dogs against the animals' DNA profiles. The hope is that genetic links will emerge to conditions such as canine compulsive disorder and canine cognitive dysfunction - a dog analogue of dementia and possibly Alzheimer's disease. The project organizers have enrolled 3,000 dogs so far, but hope to gather data from at least 5,000, and they expect to begin analysing DNA samples in March.

"It's very exciting, and in many ways it's way overdue," says Clive Wynne, who studies canine behaviour at Arizona State University in Tempe.

Researchers have long struggled to find genetic links to human psychiatric disorders by analysing DNA samples from thousands of people. Those efforts have in recent years met with some success in schizophrenia and depression. But for some conditions, including OCD, not a single robust genetic link has been sifted from the background noise of normal genetic variation.

Human studies are difficult in part because the species is so genetically diverse, says Wynne. Dogs, however, are more genetically homogeneous. Selected over thousands of years for particular characteristics, they display less genetic variation than do humans. Pure-bred dogs, in particular, have been rendered highly genetically consistent to achieve a homogenous appearance and behaviour.

Dogs also live side-by-side with humans, which some think can make them a better 
model for human disorders than mice living in a laboratory cage.

These qualities have made dogs attractive targets for studies of analogues to human ailments, including epilepsy, cancer and various psychiatric disorders. Border collies, for example, may over-react to loud noises in a manner akin to people with anxiety disorders. Geneticist Elinor Karlsson of the University of Massachusetts Medical School in Amherst and her colleagues have studied canine compulsive disorder, a condition that is particularly common in certain breeds, including Dobermann pinschers. Their studies in 150 dogs have found possible links to four genes that encode proteins that act in the brain ( $\mathrm{R}$. Tang et al. Genome Biol. 15, R25; 2014).

To expand on those results, Karlsson has decided to go big. Limiting her studies to specific breeds would make it easier to pick out some genetic links, but others might be missed. So Karlsson and her colleagues, including Jesse McClure, a former dog trainer for the US Marine Corps, decided to collect data from mongrels as well as pure-bred dogs and to crowdsource the data collection.

That focus on mixed-breed dogs is unusual but shrewd, says Adam Boyko, a geneticist at Cornell University in Ithaca, New York. Although more than half of the dogs in the United States are mongrels, genetic studies tend to focus on pure-bred animals. "Genetics often deals with the interactions between genes," says Boyko. "And if you want to truly understand those, you want to study individuals where you've shuffled up the genes."

Human participants in Darwin's Dogs, which launched last October, answer about 130 questions about their pets' behaviour. The questions cover everything from 'Does your dog generally enjoy life?' (the answer, says Karlsson, is overwhelmingly 'yes') to 'Does your dog cross its paws when it lies down?'. Some questions were inspired by surveys that assess impulsivity in humans. Other questions have been suggested by Alonso, who is the executive director of the International Association of Animal Behavior Consultants in Cranberry Township, Pennsylvania, and by other dog trainers on the basis of observations made over decades of working with animals that have behavioural problems.

Karlsson says that she is thinking of expanding the list of questions even further.

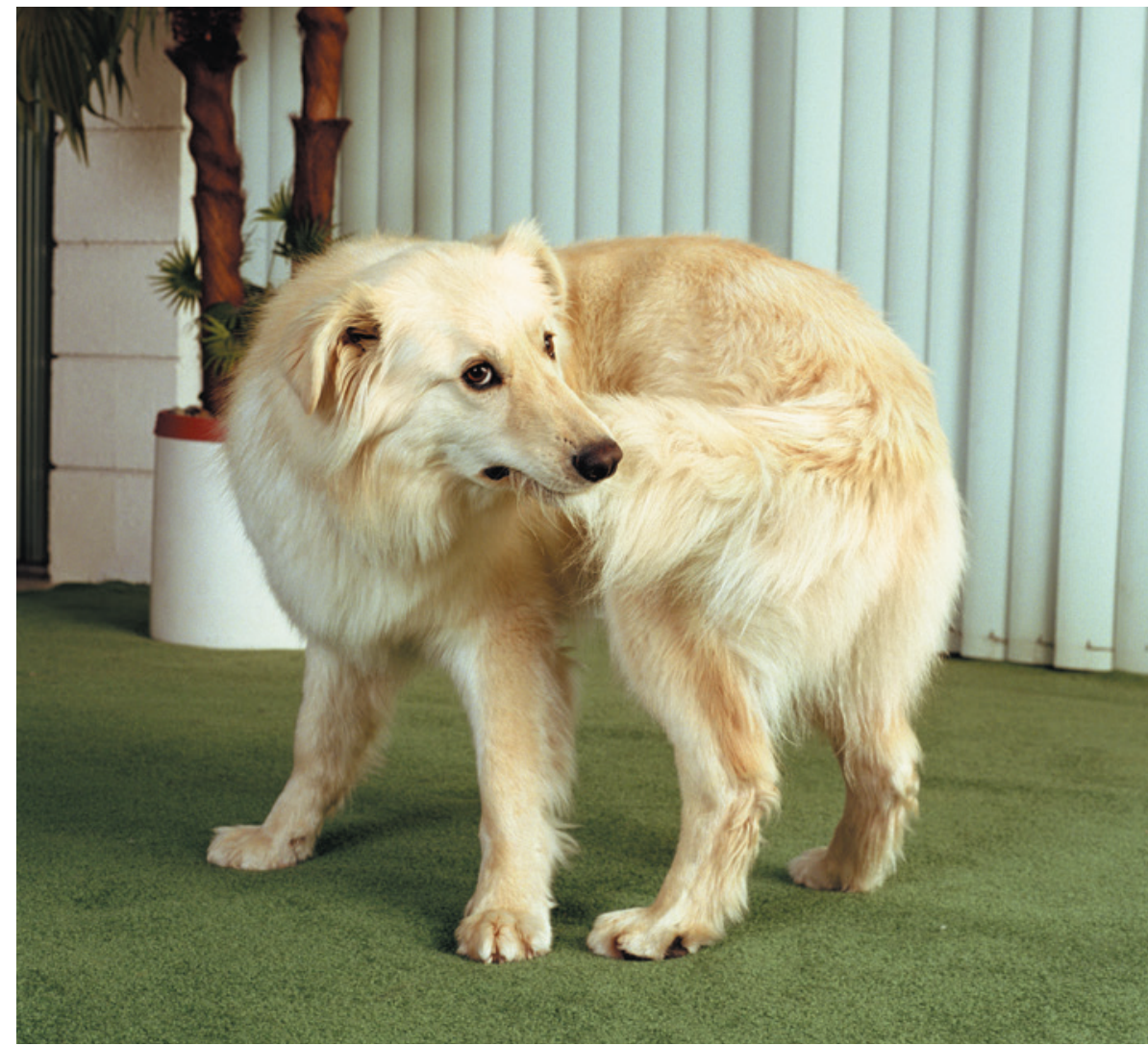

Tail-chasing in dogs is suspected to share genetic roots with human obsessive-compulsive disorder.

"Fortunately, it turns out that people love to talk about their dogs," she says.

Ultimately, the success of the project may hinge on the quality of those surveys and the specificity of the questions asked, says Wynne. Asking owners whether their dog is happy, for example, could yield mixed results. "One person's unhappy dog is another person's comfortably resting dog," he says. "A good question would be: 'Does your dog poop on the carpet?' Because poop on the carpet is pretty damn clear."

It is still unclear how useful the results from dogs will be in shedding light on human behavioural variation. Karlsson is hopeful that even if different genes are involved in the two species, they may converge on the same cellular pathways. Gerald Nestadt, a psychiatrist who specializes in OCD at Johns Hopkins University in Baltimore, Maryland, notes that affected animals often display only one type of compulsive behaviour, whereas a human with
OCD will typically have several.

Even so, he adds, the field is hungry for any leads it can get. "Anything that will help is worth trying," he says. "I think this project is a great idea."

For their part, Alonso and other participants are eager to learn more about their own dogs and why they behave the way they do. Miranda Workman of Buffalo, New York, enrolled her three dogs - Zeus, Athena and Sherlock - into the study, in part to gain insight into their behavioural quirks. Although Athena, a 34-kilogram Dutch shepherd, was bred to be a dedicated herding and guarding $\mathrm{dog}$, she has a jovial side that is not often found in her breed. And Sherlock, a Jack Russell, is more shy and sensitive than other terriers.

"I have some dogs that don't necessarily fit the stereotype," says Workman. "Is it their environment that's different or are they different? It will be fun to find out why they are that way."

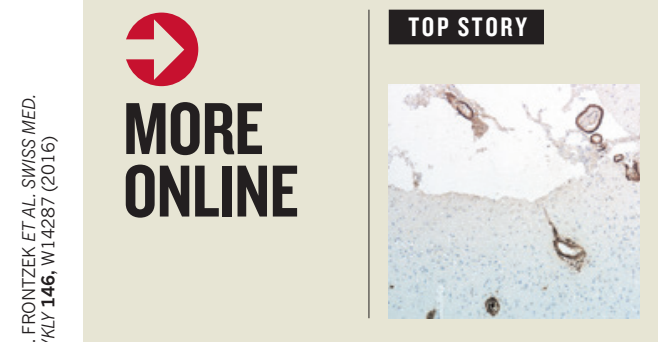

More

evidence for

'transmissible

Alzheimer's'

theory

go.nature.com/

j05gnx

\section{MORE NEWS}

- Study tallies 'true catch' of global fishing go.nature.com/aallcz

- Researchers question design of fatal French clinical trial go.nature.com/phbt9v

- End in sight for decade-long

chemistry paper controversy go.nature. com/6zm95u

\section{NATURE PODCAST}

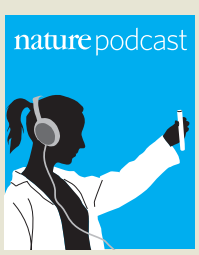

The computer program that plays Go, a general 'ageing' factor and the stolen library of John Dee. nature. com/nature/podcast 